Original Contribution

\title{
DEPENDENCIES BETWEEN MORPHOLOGICAL INDICATORS AND EARLY RIPENESS OF GREENHOUSE TOMATOES AT DIFFERENT LEVELS OF FERTILIZATION AND DILFERENT WATER SUPPLY
}

\author{
A. Stoyanova ${ }^{1 *}$, V. Kuneva ${ }^{2}$, M. Georgiev ${ }^{1}$, N. Valchev ${ }^{1}$ \\ ${ }^{1}$ Faculty of Agriculture, Trakia University, Stara Zagora, Bulgaria \\ ${ }^{2}$ Faculty of Economics, Agricultural Universiy, Plovdiv, Bulgaria
}

\begin{abstract}
The purpose of this study is to determine the impact of controlled permanent water deficiency and three levels of fertilization on earliness and total yield of tomatoes, greenhouse production using different mathematical approaches. In order to evaluate the morphological manifestations, the early harvest and the total yield under the influence of different irrigation and nutritional regimes, a tomatoes variety "Vitelio" was used. The irrigation is done with a drip irrigation system. Against the background of the same fertilizing rates in the variants with different irrigation norms there is a decrease in the early stage with an increase of the irrigation norms. A high correlation between plant height and total yield, with correlation coefficient $(r=0.899)$ and between sheet count and total yield $r=0.824$ was found.

There was a negative correlation between the first and third harvests and the total yield, respectively with correlation coefficients $r=-0.724$ and $r=-0.704$. The nature of the linear relationship between plant height and total yield is determined by the coefficient $\mathrm{R}^{2}=0.8$. Based on a two-factor analysis, it was found that irrigation regime had a dominant influence on the two parameters considered: height and yield, which was statistically proven with a very high degree of confidence $(p \leq 0.001)$.
\end{abstract}

Key words: tomatoes, drip irrigation, fertilization, yield, earliness, correlation.

\section{INTRODUCTION}

The water resources are decreasing on a global scale. The water scarcity is rising along with population growth, climate change and environmental pollution. Global water consumption has increased sevenfold in the 20th century. The largest water consumers are the industry, the agriculture, and the domestic sector. Bulgaria's fresh water resources are about 14.000 $\mathrm{m}^{3} /$ year average per person who places the country among the top 10 European countries. Nevertheless, certain areas of the country may experience water shortages due to the uneven territorial allocation of resources (1).

Tomato (Solanum Lycopersicum L.) is an important and popular vegetable grown worldwide. The tomatoes are cultures that are sensitive to irrigation. The vegetable crops do not tolerate drought or over-wetting of the soil.

\footnotetext{
*Correspondence to: Antoniya Stoyanova, Faculty of Agriculture, Trakia University, 6000, Stara Zagora, Telephon: 042/699495, toni_1219@abv.bg
}

Optimizing moisture insurance is a guarantee of high yields and quality production. The regulating of water scarcity is a problem studied by many authors.

Kuşçu et al. (2) establish the positive influence of the optimal water regime. They determine yield parameters and the effect of irrigation water at water scarcity. Taking into account the phenological development of the plants and the quality of the tomato fruits, the impact of the water deficit on the productivity of the crop and the irrigation water productivity was established. Linear relationships between yields, variants irrigated with a drip irrigation system, with different irrigation regimes have been demonstrated.

The parameters of the irrigation regime, water productivity and quantity of production have been established (3-6). Data obtained from an irrigated irrigation regime as a result of reduced irrigation rates and between irrigation periods provide useful indications of the possibility of 
improving the nutritional quality of tomatoes by reducing the irrigation rate.

In the South Italy, where water deficiency is an important problem in tomato cultivation, according to Favati et al. (7), the best compromise between the quality and quantity of the fruit to be processed is achieved by extending the irrigation interval (L40 or L60) or by limiting the irrigation volume for the second part of the tomato crop cycle (thesis 100-50). The extension of the period between the irrigation period and the reduction of the irrigation norms for the period from the 1st to the last harvest is outlined as a perspective strategy for managing the irrigation regimes in tomatoes, parameters of tomatoes and the amount of irrigated water.

Ensuring the optimal development of tomatoes with minimal negative effect on the environment is possible if the needs of the plants in the different stages of vegetation are properly specified. The determination of the amount of nutrients needed to build up the yield allows for proper justification of the recommended fertilizer norms (8-10). Regardless of the numerous researches in Bulgaria and abroad, related to the growth and productive manifestations of tomatoes, as well as to the various norms, forms and methods of fertilization, there is still no algorithm for exact and correct determination of fertilizer norms.

The agriculture is a large consumer of fresh water in competition with other sectors of society (11). Within the EU SAFIR project new waterbased watering strategies based on experiments with tomatoes (Lycopersicon esculentum Mill); and other crops have been developed. The findings during the SAFIR project can be used as a framework for the implementation of watersaving technologies under different soil and climatic conditions.

One of the most powerful agro-technical factors for increasing yields per unit area is fertilization. As a result of a number of studies conducted on different crops, dependencies have been identified that determine the parameters of optimal fertilization to obtain optimal yields. In excessive use of chemical fertilizers, soil contamination can reach serious levels.

The soil substrate has accumulated harmful toxic residues as a consequence of their annual introduction together with the main fertilization (12). One of the goals of environmentally friendly farming is the application of innovative methods and practices for balanced fertilization and irrigation of plants in order to obtain quality production.
The purpose of this study is to determine the impact of controlled permanent water deficiency and three levels of fertilization on early harvest and total yield of tomatoes, greenhouse production using different mathematical approaches.

\section{MATERIAL AND METHOD}

To determine the impact of different fertilization and fertilization modes, an experience with greenhouse tomatoes has been carried out. The study was conducted under controlled conditions. In order to evaluate the morphological manifestations, the earliness-and the total yield under the influence of different irrigation and nutritional regimes, a tomatoes variety "Vitelio" was used. This is an indeterminate variety of Syngenta suitable for growing in a polyethylene greenhouse. Experience is based on the block method. The size of the plot was $10 \mathrm{~m}^{2}$, planted on a flat surface according to design $110+50+$ 35 (13). The study was conducted during the period 2016-2017. The pots in all variants are given at the same time, the irrigation rate being in accordance with the requirements for the respective option. Irrigation was carried out with a drip irrigation system with built-in drippers at a distance of $0.10 \mathrm{~cm}$. In accordance with the method requirements in the first year, 33 irrigations with irrigation rate at the optimal irrigation variant of $49.5 \mathrm{~m}^{3} /$ ha were realized. In the second year they are submitted 27 irrigations with the size of the irrigation rate $40.5 \mathrm{~m}^{3} / \mathrm{ha}$.

The experimental variants are: 1. Irrigated irrigation regime $(50 \%$ of the irrigation rate) without fertilization. 2. Irrigated irrigation regime (75\% of the irrigation norm) without fertilization. 3. Optimal irrigation regime (M$100 \%$ ) without fertilization (control). 4. Broken irrigation regime $(50 \%$ of irrigation rate) and $50 \%$ fertilization. 5. Broken irrigation regime (75\% of irrigation rate) and 50\% fertilization; 6 . Optimal irrigation regime (M-100\%) with 50\% fertilization. 7. Broken irrigation regime $(50 \%$ of the irrigation rate) and $75 \%$ fertilization. 8 . Broken irrigation regime (75\% of irrigation rate) and $75 \%$ fertilization. 9. Optimal irrigation regime $\mathrm{M}-100 \%)$ with $75 \%$ fertilization. 10. Irrigated irrigation regime $(50 \%$ of irrigation rate) and $100 \%$ fertilization. 11. Broken irrigation regime $(75 \%$ of irrigation rate) and $100 \%$ fertilization. 12 . Optimal irrigation regime (M-100\%) and $100 \%$ fertilization.

Tomatoes, greenhouse production, are crops that require high levels of fertilization. For the purposes of the experiment, variants with basic fertilization and feeding with different nutrient rates are laid down. The main fertilization was carried out with $\mathrm{P}_{23}$ (in the form of $\mathrm{P}_{2} \mathrm{O}_{5}$ ) and $\mathrm{K}_{25}$ 
(as $\mathrm{K}_{2} \mathrm{SO}_{4}$ ). Feeding through vegetation was performed with $\mathrm{N}_{50}$ (as $\mathrm{NH}_{4} \mathrm{NO}_{3}$ ) and $\mathrm{K}_{66}$ (as $\mathrm{KNO}_{3}$ ), according to the experimental methodology.

During tomato vegetation, greenhouse production, the morphological and phenological features of the plants in the various feeding and irrigation options were studied: stem height, number of leaves formed, number of inflorescences, number of wounds.. During the two years of the study, the duration of the planting period to the 1 st harvest and the period from the 1 st to the last harvest was determined.

The assessment of the effects of fertilization and irrigation regimes is based on the following morphological indicators: $\mathrm{x}_{1}$ - height; $\mathrm{x}_{2}$ - number of sheets; $\mathrm{x}_{3}$ - number of inflorescences; $\mathrm{x}_{4}$ - first harvest; $\mathrm{x}_{5^{-}}$second harvest; $\mathrm{x}_{6^{-}}$third harvest; $\mathrm{x}_{7^{-}}$ total yield. The data for the structural elements of the yield was obtained on the basis of measurements made on 10 repeating plants in all variants of the assay.
Yields are reported by weight at harvest dates, by variants, $\mathrm{kg} / \mathrm{ha}$.

The results are subjected to a dispersion analysis using the Statgraphics statistical package. The processing was performed with the SPSS 13 statistical program.

\section{RESULTS AND DISCUSSION}

In the first year, the duration of the planting period to the 1 st harvest is 84 days, and the period from the first harvest to the last is 70 days.

For the second year, the planting period up to the 1st harvest was established for 80 days, with a difference of 4 days compared to the first year. The second period, covering the 1st to the last harvest, was recorded for 60 days. The duration of the vegetation period also determines the size of the irrigation rate, which is $18 \%$ lower with 140 days vegetation. The parameters of tomato harvesting, greenhouse production, cultivated under conditions of irrigated irrigation regime and different fertilization norms have been established.

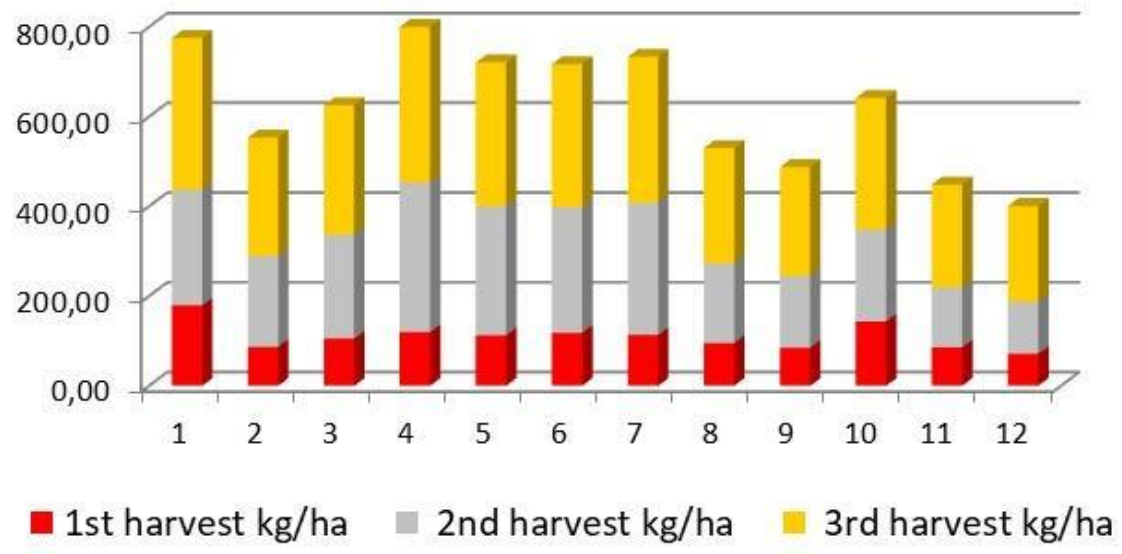

Figure 1. Economic early maturity of tomatoes, greenhouse production for 2016

The results of the morphological analysis show that in terms of plant height the variants that are fermented exceeded the net control by $6.1 \%$ to
$20.5 \%$. Strong plant growth occurs with $75 \%$ and $100 \%$ fertilization and irrigation with reduced $(75 \%)$ and optimal irrigation (Variant 12$).$

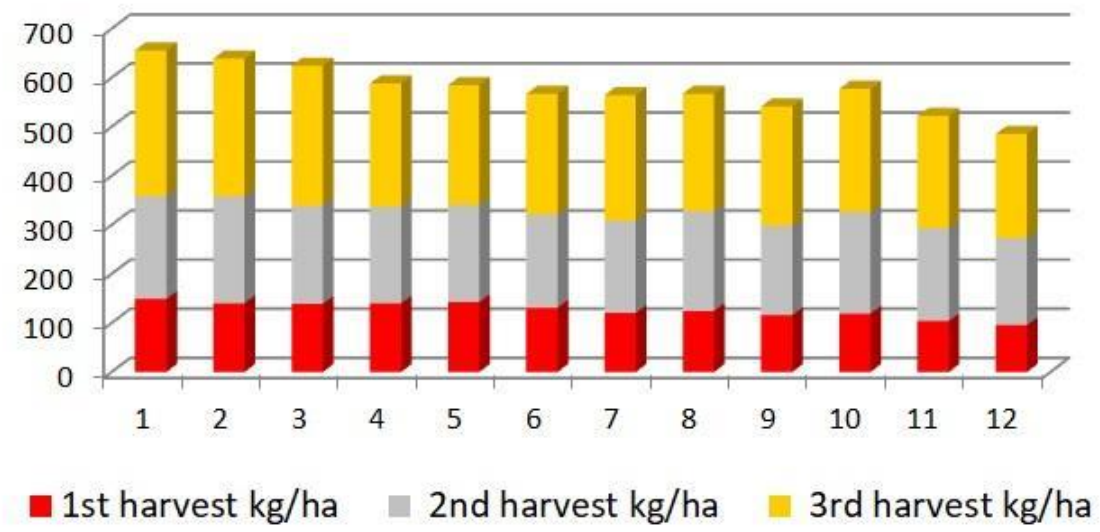

Figure 2. Economic early maturity of tomatoes, greenhouse production for 2017 

Similar are the tendencies for the number of leaves formed from one plant. Morphological analysis data reflects the impact of different fertilization and irrigation regimes on nutrient uptake and leaf-plant weight formation of plants. The investigations from several studies showed that gradual soil drying imposed by deficit irrigation (DI) or partial root zone drying irrigation (PRD) induced hydraulic and chemical signals from the root system resulting in partial stomatal closure, an increase in photosynthetic water use efficiency, and a slight reduction in top vegetative growth, (Jensen et al. 2010).

It was found that fertilizing with $75 \%$ of the fertilizer rate, with a 50\% reduction in irrigation regime (Variant 7), contributed to the best plant cellularity in the first experimental year. In the second year, the conditions for feeding and irrigation favor the formation of the largest vegetative mass in optimal fertilization and irrigation (Variant 12). The analysis of the twoyear results shows an increase in the number of inflorescences in increasing the moisture content.

At the optimal irrigation rate, a reduction of the number of inflorescences was registered by $12.5 \%$ compared to the variant with a reduced $(75 \%)$ irrigation rate. Knowing the vegetative events is a prerequisite for accurately determining the size of the food area and properly regulating the food and irrigation regime. The balanced ratio between leaf-berry mass and the number of flowers, respectively, fruit juice guarantees the synthesis of enough plastic substances, ensuring a high yield at high economic maturity.

The analysis of the results for early culture shows that the share of the second harvest is greatest during the first experimental year (Figure 1). In the second year, the third portion is characterized by the third harvest (Figure 2). Highest economic premise is observed at the unfertilized and half-irrigation rate (Variant 1). On average, for the high-erosion period, the option with halfirrigation and fertilization (Variant 4) stands out too. For all other options, economic is lower than in the control.

Against the background of the same fertilizing rates in the variants with different irrigation norms there is a decrease in the early stage with an increase of the irrigation norms. Compared to fertigation frequency, irrigation frequency seems to be the main factor affecting $\mathrm{N}$ recovery at high fertilizer-N rate, according to Farneselli et al. (14). Thus, high fertigation and/or irrigation frequency may represent a strategy to increase $\mathrm{N}$ uptake efficiency in processing tomato fed with very high $\mathrm{N}$ and water supply, which is often the case in intensive cultivation of tomatoes. With the increase of the fertilizer rate in the same irrigation regime, the economic decreases, the lowest in the maximum nutrition and water regime (Variant 12). However, the opinion of Gölgen (15) is that reduced potassium doses lead to decreased growth of roots, yields and delay in fruit maturation.

Variation analysis of the results for first, second and third harvests take into account the limits of variation in yields for individual harvests (Table 1). Results of the resulting variability between the studied indicators are presented. The lowest value was observed at the first harvest in 2016 (x $=7.12$ ), and the highest at third harvest in 2017 $(x=34.66)$. The coefficient of variation $(\mathrm{CV})$ provides information on the dispersion of the attribute, and is also used to assess the homogeneity of the sample. For the first, second and third harvest for 2017, the sample is homogeneous. For 2016 on the first and second harvest, the sample is highly inhomogeneous.

Table 1. Variation of economic early maturity in greenhouse tomatoes for the period 2016-2017

\begin{tabular}{|c|c|c|c|c|c|c|}
\hline \multicolumn{7}{|c|}{ First harvest } \\
\hline & $\mathrm{N}$ & Min & Max & $\bar{x}$ & $S$ & $\mathrm{CV}, \%$ \\
\hline 2016 & 12 & 7.12 & 17.88 & 10.95 & 29.5 & 27 \\
\hline 2017 & 12 & 9.55 & 14.86 & 12.66 & 16.5 & 13 \\
\hline \multicolumn{7}{|c|}{ Second harvest } \\
\hline 2016 & 12 & 11.60 & 33.40 & 22.35 & 69.1 & 31 \\
\hline 2017 & 12 & 17.79 & 21.83 & 19.68 & 11.8 & 6 \\
\hline \multicolumn{7}{|c|}{ Third harvest } \\
\hline 2016 & 12 & 21.19 & 29.74 & 25.28 & 24.3 & 10 \\
\hline 2017 & 12 & 21.36 & 34.66 & 28.6. & 44.6 & 16 \\
\hline
\end{tabular}




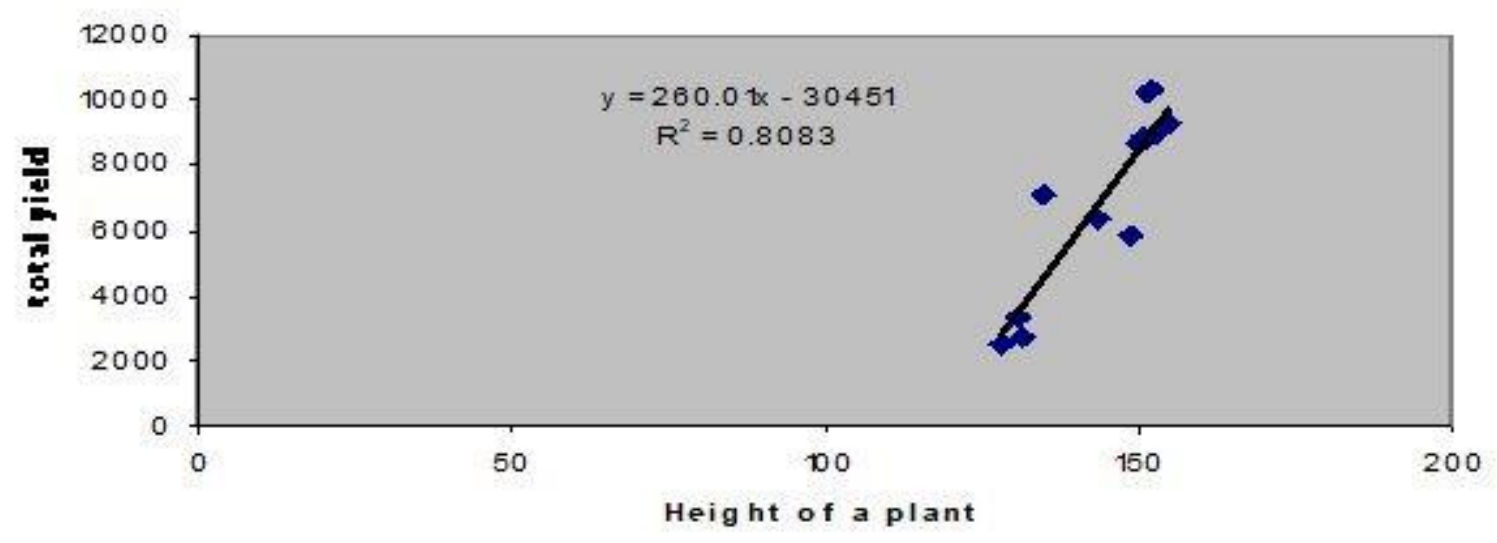

Figure 3. Regression dependence between height and total yield

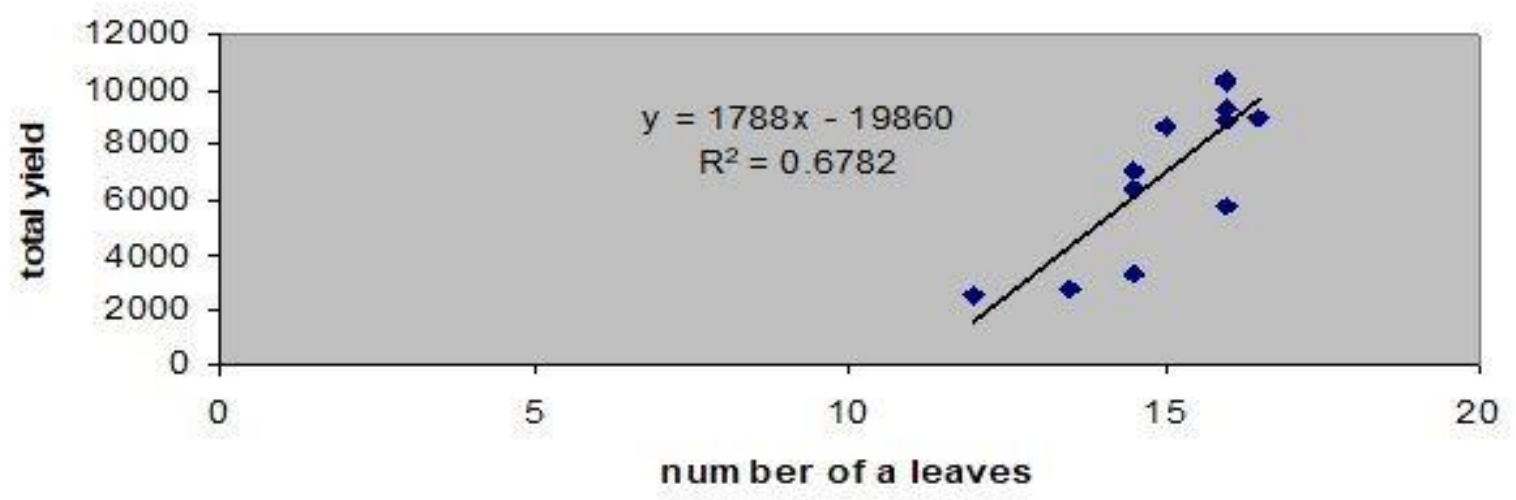

Figure. 4. Regression dependence between number of leaves and total yield

A correlation analysis was carried out, which established and evaluated the correlation between the investigated indicators expressed by the correlation coefficient (r). Correlational dependencies are a product of mathematical and statistical processing of Genchev's output data, etc. (1975).

Correlation coefficients (r) have been calculated.

The dependence of the magnitude of the yield on the traits was measured by correlation coefficient values. A positive correlation was found between plant height and leaf number, plant height and total yield; number of leaves and total yield; third harvest with first and second harvest (Table 2). The calculated correlation coefficients between the leaves weight and the total yield clarify the origin of the relationship between the growth and production patterns of tomatoes grown in greenhouse conditions.

It is established a negative correlation between the indicators: height of the plant and first harvest; number of leaves and first harvest; total yield and first and third harvest.

The correlation coefficient gives a general idea of the extent and direction of dependence between the underlying parameters. Along with the correlation analysis, quantitative regression was performed. Regression relationships show that it is linear, which means that by increasing some of the attributes by unit this will result in a constant change (decrease or increase) in yield. In this case the linear dependence, with coefficient $\mathrm{R}^{2}=$ 0.8 , establishes that the increase of the height of the stems increases also the size of the total yield, characterizing the early tomatoes, greenhouse production. The linear regressions between the relative parameters of fruit quality and relative evapotranspiration, found Yang et al. (2017) in a study of irrigation of tomatoes in a controlled water deficit. Dependencies are the basis of developing a strategy for irrigation of tomatoes in a water deficit in greenhouse conditions.

The two-factor analysis establishes the influence of the year and the various irrigation regimes on the height of the plants and on the yield of the three harvests. In the two experimental years different irrigation norms have been implemented, depending on the length of the vegetation period. The analysis found $40-44 \%$ influence of irrigation factor. Table 3 presents the results of the data for yields-during the 20162017. 
STOYANOVA A., et al.

Table 2. Correlational relationships between morphological indicators and early maturity of tomatoes

\begin{tabular}{|c|c|c|c|c|c|c|c|c|}
\hline Indicators & & Height & $\begin{array}{l}\text { Number } \\
\text { of } \\
\text { sheets }\end{array}$ & $\begin{array}{l}\text { Number } \\
\text { of } \\
\text { inflores } \\
\text { cences }\end{array}$ & $\begin{array}{l}\text { First } \\
\text { harvest }\end{array}$ & $\begin{array}{l}\text { Second } \\
\text { harvest }\end{array}$ & $\begin{array}{l}\text { Third } \\
\text { harvest }\end{array}$ & $\begin{array}{l}\text { Total } \\
\text { yield }\end{array}$ \\
\hline & $X_{i}$ & $x_{1}$ & $x_{2}$ & $x_{3}$ & $x_{4}$ & $x_{5}$ & $x_{6}$ & $x_{7}$ \\
\hline Height & $x_{1}$ & 1 & $0.897 * *$ & 0.342 & $-0.692 *$ & -0.411 & $-0.621 *$ & $0.899 * *$ \\
\hline $\begin{array}{l}\text { Number of } \\
\text { sheets }\end{array}$ & $x_{2}$ & & 1 & 0.513 & $-0.716 * *$ & -0.321 & -0.576 & $0.824 * *$ \\
\hline $\begin{array}{l}\text { Number of } \\
\text { infloresce } \\
\text { nces }\end{array}$ & $x_{3}$ & & & 1 & -0.210 & 0.133 & 0.011 & 0.395 \\
\hline $\begin{array}{l}\text { First } \\
\text { harvest }\end{array}$ & $x_{4}$ & & & & 1 & $0.741 * *$ & $0.923 * *$ & $-0.724 * *$ \\
\hline $\begin{array}{l}\text { Second } \\
\text { harvest }\end{array}$ & $x_{5}$ & & & & & 1 & $0.917 * *$ & -0.544 \\
\hline $\begin{array}{l}\text { Third } \\
\text { harvest }\end{array}$ & $x_{6}$ & & & & & & 1 & $-0.704 *$ \\
\hline Total yield & $x_{7}$ & & & & & & & 1 \\
\hline
\end{tabular}

Table 3. Two-factor dispersion analysis of factors: $A$ - year and B - irrigation regime on the height of plants and total harvest yield

\begin{tabular}{|c|c|c|c|c|c|c|c|}
\hline $\begin{array}{l}\text { Variation } \\
\text { Source }\end{array}$ & $\begin{array}{l}\text { Influence } \\
\text { of } \\
\text { factor, } \\
\%\end{array}$ & SS & df & MS & $\mathbf{F}$ & P-value & F crit \\
\hline \multicolumn{8}{|l|}{ Height } \\
\hline Year $(\mathrm{A}) *$ & $3 \%$ & 485.68 & 1 & 485.68 & 4.29 & 0.044 & 4.04 \\
\hline $\begin{array}{l}\text { Irrigation } \\
\text { (B)*** }\end{array}$ & $44 \%$ & 6830.71 & 11 & 620.97 & 5.48 & 0 & 1.99 \\
\hline $\begin{array}{l}\text { Interaction } \\
* *\end{array}$ & $17 \%$ & 2634.82 & 11 & 239.53 & 2.11 & 0.037 & 1.99 \\
\hline Errors & & 5436.67 & 48 & 113.26 & & & \\
\hline \multicolumn{8}{|l|}{ Total yield } \\
\hline Year(A)* & $12 \%$ & 131328.1 & 1 & 131328.1 & 82.73 & 0.003 & 4.04 \\
\hline $\begin{array}{l}\text { Irrigation } \\
(\mathrm{B}) * * *\end{array}$ & $40 \%$ & 446849.8 & 11 & 40622.7 & 25.9 & 0 & 1.99 \\
\hline $\begin{array}{l}\text { Interaction } \\
* * *\end{array}$ & $41 \%$ & 459047.6 & 11 & 41731.6 & 26.29 & 0 & 1.99 \\
\hline Errors & & 76198.9 & 48 & 1587.5 & & & \\
\hline
\end{tabular}

For the indicator "height" (Table 3), the greatest influence of factor B is observed, a dominant mode of dominance of $44 \%$ and a proven significant $\mathrm{p} \leq 0.001$ on the change of the indicator. Second is the interaction between the two factors with an impact of $17 \%$.

The biometric indicator "yield" is a power effect of $41 \%$ of the irrigation regime and the interaction between the two factors at $\mathrm{p} \leq 0.001$.
The influence of factor $\mathrm{A}$ is of secondary importance $(p \leq 0.05)$. Independent-influence of factor $\mathrm{A}$ is not considered.

\section{CONCLUSIONS}

Against the background of the same fertilizing norms in the variants with different irrigation norms there is a decrease in the early age with an increase of the irrigation norms. A high 
correlation between plant height and total yield, with correlation coefficient $r=0.899$ and between sheet count and total yield $r=0.824$ was found.

There was a negative correlation between the first and third harvests and the total yield, respectively with correlation coefficients $\mathrm{r}=$ 0.724 and $r=-0.704$.

The nature of the linear relationship between plant height and total yield is determined by the coefficient $\mathrm{R}^{2}=0.8$.

Based on a two-factor analysis, it was found that irrigation regime had a dominant influence on the two parameters considered: height and yield, which was statistically proven with a very high degree of confidence $(\mathrm{p} \leq 0.001)$.

\section{REFERENCES}

1. National Report on the Status and Protection of the Environment in the Republic of Bulgaria in 2011 (Edition 2013).

2. Kuşçu, H., Turhan, A., Demir, A. O., The response of processing tomato to deficit irrigation at various phenological stages in a sub-humid environment. Volume 133. Agricultural Water Management., 92-103, 2014.

3. Ngouajio M., Wang, G., Goldy, R., Withholding of drip irrigation between transplanting and flowering increases the yield of field-grown tomato under plastic mulch. Agricultural Water Management. Volume 87, Issue 3, 285-291, 2007.

4. Nangare, D.D., Singh, Y., Kumar, P. S., Minhas, P.S., Growth, fruit yield and quality of tomato (Lycopersicon esculentum Mill.) as affected by deficit irrigation regulated on phenological basis. Agricultural Water Management. Volume 171, 73-79, 2016.

5. Marouelli, W., Silva, W. LC., Water tension thresholds for processing tomatoes under drip irrigation in Central Brazil. Irrigation Science 25(4):411-418, 2007.

6. Yang, H., Du, T., Qiu, R., Chen J., Wang, F., Li, Y., Wang, C., Gao, L., Kang, S., Improved water use efficiency and fruit quality of greenhouse crops under regulated deficit irrigation in northwest China. Agricultural Water Management. Volume 179, 193-204, 2017.
7. Favati, F., Lovelli, S., Galgano F., Miccolis, V., Tommaso, T. D., Candido, V., Processing tomato quality as affected by irrigation scheduling. Scientia Horticulturae. Volume 122, Issue 4, 562-571, 2009.

8. Hartz, T., Fertility Management of Processing Tomato. Plant \& Soil Conference, p.71-75, 2007.

9. Nikolov, N., Cholakov, D., Moskova, Christova T. D., Optimizing the nitric nutrition of tomatoes cv. Rila F1, grown in an unheated plastic greenhouse, by using modified granules which contain polymers and black sea sapropelles. Agricultural University - Plovdiv, Agricultural Sciences Vol. III, Issue 5, 29-32, 2011.

10. Mitova, Iv., N. Dinev., Effect of potassium fertilization on the dynamics of fruit production and the yield of determinant varieties and hybrids of tomatoes. Soil Science, Agrochemistry and Ecology, No 2, 42-49, 2012.

11. Jensen C. R., Battilani, A., Plauborg, F., G. Psarras, K. Chartzoulaki, F. Janowiak, R. Stikic, Z. Jovanovic, G. Li, X. Qi, F. Liu, S.E. Jacobsen, M.N. Andersen., Deficit irrigation based on drought tolerance and root signalling in potatoes and tomatoes. Agricultural Water Management, Volume 98, Issue 3, Pages 403-413, 2010.

12. Borrows H.I., Soil pollution and its influence on plant quality. J. Soil Water Conserv. v. 21, p. 76-112, 1966.

13. Barov, B., Analysis and schemes of field experience. NAPS, Sofia. 1982.

14.Farnesell, M., Benincasa, P., Tosti, G., Simonne, E., Guiducci, M., Tei, F. 2015. High fertigation frequency improves nitrogen uptake and crop performance in processing tomato grown with high nitrogen and water supply. Agricultural Water Management. Vol. 154, 31, 52-58, 2015.

15. Gölgen, D. S. 2012. Scientia Horticulturae. Volume 149, 4 January 2013, Pages 70-79. Rootstocks can enhance tomato growth and quality characteristics at low potassium supply Dietmar Schwarza Gölgen Bahar Öztekin YükselTüzel Bernhard Brücknera Angelika Krumbeina https://doi.org/10.1016/j.scienta.2012.06.013

16. Genchev, D., Marinkov, E., Freedman, B., Ognyanova, A. Biometric methods in crop, genetics and breeding. Zemizdat, Sofia. 1975. 